https://journal.uwgm.ac.id/index.php/abdimasmahakam

E-ISSN: 2549-5755

Januari 2020, Vol. 4 No. 01

Received: September 2019

Accepted: Desember 2019

Published: Januari 2020

Article DOI: http://dx.doi.org/ 10.24903/jam.v4i1.781

\title{
Olahan Sari Jeruk sebagai Usaha untuk meningkatkan Nilai Produk Jeruk Siam
}

\author{
Tri Wahyu Oktavendi \\ Universitas Muhammadiyah Malang \\ twoktavendi@umm.ac.id \\ Firda Ayu Amalia \\ Universitas Muhammadiyah Malang \\ firdaayu@umm.ac.id
}

\begin{abstract}
Abstrak
Tujuan dilakukannya kegiatan pengabdian masyarakat ini adalah untuk meningkatkan nilai produk jeruk siam di Desa Gading Kulon, Kecamatan Dau, Kabupaten Malang. Latar belakang yang mendasari dilakukannya pengabdian oleh tim adalah adanya permintaan dari para petani jeruk di daerah tersebut. Para petani yang selanjutnya disebut mitra meresahkan anjloknya harga jeruk ketika panen raya. Keresahan inilah yang ditindaklanjuti oleh tim pengabdian. Mitra telah mendapatkan sosialisasi olahan jeruk. Akan tetapi tidak ada proses yang berkelanjutan. Harapan mitra adalah adanya proses pendampingan produksi hingga pemasaran sari jeruk. Pengabdian yang dilakukan sekarang adalah tahap pertama, yaitu melaksanakan pelatihan membuat olahan sari jeruk. Metode yang digunakan adalah praktik secara langsung dengan mengundang pemateri yang ahli di bidang pengolahan sari buah. Produk olahan sari jeruk telah tercipta melalui tahapan yang sudah dilakukan. Tahapan tersebut dimulai dari sosialisasi hingga praktik pembuatan produk sari jeruk. Sebelum dilaksanakannya proses pengolahan, terlebih dahulu pemateri memaparkan materi yang berisi alat dan bahan yang digunakan serta langkah-langkah pembuatan sari jeruk. Proses pengolahan sari jeruk dilaksanakan selama 2 jam. Hasilnya, produk olahan sari jeruk tercipta dan mampu meningkatkan nilai produk Jeruk Siam. Pemateri memberikan kesempatan pada peserta pelatihan untuk mencoba hasil olahan sari jeruk. Selain itu, membuka sesi evaluasi pada peserta pelatihan atas olahan sari jeruk yang dihasilkan.
\end{abstract}

Kata Kunci: Olahan Sari Jeruk; Petani Jeruk; Diversifikasi Produk .

\section{Pendahuluan}

Pada bahasan perekenomian Indonesia, sektor pertanian merupakan salah satu sektor penting dan vital (Hermawan, 2012; Isbah \& Iyan, 2016; Putra \& Nasir, 2015). Berdasarkan informasi yang dikutip dari berita detik.finance.com, tanggal 03 Juli 2017 bahwa sektor pertanian merupakan sektor kedua yang menunjang peningkatan Produk Domestik Bruto (PDB). Pada triwulan II Tahun 2017, PDB mengalami pertumbuhan sebesar 5,01\%, yang 


\section{(A) ABDIMAS \\ https://journal.uwgm.ac.id/index.php/abdimasmahakam}

E-ISSN: 2549-5755

Januari 2020, Vol. 4 No. 01

mana sektor pertanian mengalami pertumbuhan sebesar 3,33\% (ditjenpkh.pertanian.go.id). Pada tahun 2045, Indonesia menjadi sumber pangan di tingkat internasional. Hal tersebut merupakan visi pemerintah. Oleh karena itu, sektor pertanian menjadi penting untuk ditunjang agar mencapai visi tersebut.

Kegiatan pertanian meliputi budidaya tanaman bahan makan, perkebunan, perikanan, kehutanan dan peternakan (Alitawan \& Sutrisna, 2017). Fokus pada proposal ini adalah pada sektor pertanian. Lebih spesifik yaitu pada bidang perkebunan jeruk. Alasan yang menjadi dasar pengusul memilih perkebunan jeruk adalah daerah tempat tinggal pengusul merupakan salah satu penghasil jeruk terbesar di Malang. Daerah penghasil jeruk tersebut bertempat di Desa Gading Kulon, Kec. Dau. Terlepas dari itu, berdasarkan berita detik.finance.com tanggal 23 Agustus 2017, disebutkan bahwa pertumbuhan sektor pertanian merupakan pertumbuhan tertinggi dan hal ini ditunjang dengan meningkatnya beberapa komoditas, termasuk salah satunya dari holtikultura.

Kualitas jeruk siam tidak dapat mengimbangi jumlah komdoditas jeruk. Persaingan antara jeruk lokal dengan jeruk impor masih didominasi oleh jeruk impor. Berdasarkan data dinas pertanian, tahun 2007 hingga 2014, impor jeruk cenderung mengalami kenaikan. Pertumbuhan volume impornya, rata-rata sebesar $81,93 \%$ per tahun. Hal ini dikarenakan rasa jeruk lokal yang kurang enak, penampilan jeruk yang tidak menarik, dan produksi yang tidak menentu (balitjestro.litbang.pertanian.go.id). Sehingga harga jual jeruk lokal kalah bersaing dengan jeruk impor.

Salah satu provinsi yang memiliki area atau luas panen jeruk siam terbesar di Indonesia adalah Jawa Timur (Statistik Pertanian 2017). Dengan kata lain, Jawa Timur berkontribusi sangat besar dalam memproduksi jeruk siam. Namun, jeruk siam yang dihasilkan belum mampu mengungguli jeruk impor. Oleh karena itu, diperlukan inovasi produk olahan jeruk siam. Hal ini bertujuan untuk meningkatkan daya saing dan nilai jual dari hasil panen jeruk siam.

Kota Malang salah satu penghasil jeruk siam dengan luas lahan \pm 740 Ha (dau.malangkab.go.id). Desa Selorejo, Gading Kulon, Petung Sewu, dan Tegal Weru merupakan lokasi lahan penghasil jeruk siam di Malang. Desa Gading Kulon menjadi tempat pengabdian pengusul karena merupakan daerah tempat tinggal pengusul. Oleh sebab itu, pengusul mengetahui kondisi pertanian jeruk di Desa Gading Kulon. Ketika musim panen, kondisi memprihatinkan pun terjadi, yaitu harga jeruk siam menurun. Hal tersebut berdampak pada motivasi petani jeruk untuk memasarkan hasil panennya juga menurun. Salah satu upaya yang dilakukan petani jeruk adalah membuka wisata petik jeruk. Wisatawan diperbolehkan menikmati jeruk sepuasnya di tempat lokasi. Apabila wisatawan ingin membawa pulang, maka hargnya Rp. $10.000 / \mathrm{kg}$.

Harga jual tersebut termasuk harga yang relatif rendah apabila dibandingkan harga jeruk secara nasional. Tahun 2016 harga jeruk per kilo adalah Rp 15.877 (Statistik Harga Komoditas Pertanian 2017). Salah satu fenomena yang miris akibat jatuhnya harga pasar ialah banyaknya jeruk siam yang terbuang sia-sia. Menurut ketua petani jeruk siam sekitar 5$6 \mathrm{~kg}$ terbuang sia-sia karena tidak laku dan jatuh di tanah hingga membusuk.

"5-6 kg per hektar untuk jeruk yang sudah matang tapi membusuk jatuh

di tanah." Jelas Pak Prapto, Ketua Petani Jeruk di Desa Gading Kulon. 
https://journal.uwgm.ac.id/index.php/abdimasmahakam

E-ISSN: 2549-5755

Januari 2020, Vol. 4 No. 01

Jumlah tersebut seharusnya bisa dimanfaatkan untuk menciptakan produk olahan sari jeruk atau diversifikasi produk lainnya. Hal tersebut tentunya dapat meningkatkan kesejahteraan masyarakat di Desa Gading Kulon.

Petani jeruk siam di desa Gading Kulon telah mendapatkan sosialisasi terkait olahan sari jeruk dan responya pun sangat baik.

"Kami berharap kerjasama ini tidak berhenti sampai di sini saja, tetapi ada kelanjutan kegiatan khususnya dalam hal praktik.” Ungkap Pak Prapto.

Namun belum ada tindak lanjut bagaimana produk olahan sari jeruk tersebut dapat terealisasi. Kelompok tani meminta kepada pengusul untuk menindaklanjuti hal tersebut. Tindakan selanjutnya ialah mengadakan pelatihan atau praktik pengolahan jeruk siam menjadi sari jeruk. Oleh karena itu, pengusul mengajukan pengabdian untuk menindaklanjuti permasalahan tersebut.

Secara umum permasalahan yang dihadapi oleh petani jeruk di Desa Gading Kulon, Malang adalah Harga jual jeruk siam yang rendah. Berikutnya, rendahnya daya saing dan pengetahuan mitra yang masih terbatas terkait dengan pengolahan sari jeruk. Keterbatasan tersebut menimbulkan tidak adanya inovasi produk. Sehingga, banyak jeruk siam yang terbuang sia-sia. Di samping itu, belum adanya kredit usaha mikro dan keterbatasan sarana transportasi juga menjadi kendala yang dialami petani jeruk siam.

Berdasarkan permasalah yang telah diuraikan sebelumnya, yang pada intinya adalah rendahnya harga jual jeruk siam karena tidak adanya inovasi produk. Masalah tersebut harus segera diselesaikan untuk memaksimalkan daya saing, terutama terhadap jeruk impor. Dengan adanya inovasi produk olahan jeruk, pendapatan petani jeruk dapat meningkat. Berbeda dengan apabila jeruk dijual secara langsung, tanpa diolah terlebih dahulu. Kemungkinan yang terjadi apabila jeruk dijual tanpa diolah terlebih dahulu adalah harga jual yang rendah. Selain itu, terdapat kemungkinan jeruk yang telah dipanen membusuk karena terlalu lama dalam penyimpanan.

Banyak tenaga kerja di wilayah pertanian jeruk yang dapat terserap. Hal tersebut disebabkan adanya produksi sari jeruk yang memerlukan tenaga kerja untuk proses pengolahan. Sehingga jumlah pengangguran dapat berkurang. Selain itu, pendapatan per kapita penduduk wilayah tersebut dapat meningkat. Semula hanya sebagai buruh tani jeruk, tetapi dengan adanya produksi olahan sari jeruk warga dapat menjadi tenaga kerja pada usaha olahan sari jeruk. Sehingga pendapatan warga mengalami kenaikan.

\section{Metode}

Masalah yang dihadapi oleh petani jeruk, dapat diselesaikan dengan cara dilakukannya koordinasi antara pengusul dengan petani jeruk. Beberapa metode yang digunakan untuk memecahkan masalah yaitu: (1) menyelenggarakan pelatihan/praktik pengolahan sari jeruk, (2) mendampingi proses pembuatan olahan sari jeruk, dan (3) membantu untuk memperluas pemasaran dan area distribusi.

Berikut gambar 3.1 yang menggambarkan kerangka pemecahan masalah dalam Iptek bagi Masyarakat pada petani jeruk siam: 
https://journal.uwgm.ac.id/index.php/abdimasmahakam

E-ISSN: 2549-5755

Januari 2020, Vol. 4 No. 01

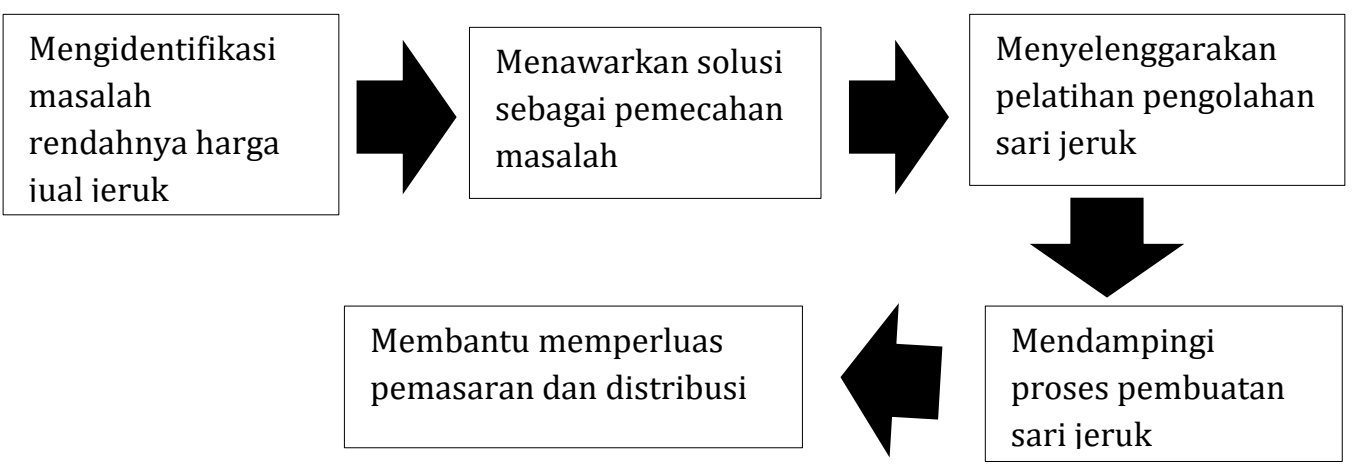

Gambar 1 Kerangka Pemecahan Masalah

Petani jeruk secara aktif berkoordinasi dengan pengusul. Koordinasi dilakukan dalam rangka penyelesaian masalah yang dihadapi oleh petani jeruk. Pentingnya koordinasi disebabkan karena petani jeruk memiliki informasi secara mendalam mengenai kondisi dan masalah pertanian jeruk. Terkait dengan tempat koordinasi, petani jeruk bersedia untuk memfasilitasi.

\section{Hasil dan Pembahasan}

Pelaksanaan pengabdian yaitu praktik pengolahan sari jeruk dilaksanakan di Balai Dusun Sempu, Desa Gading Kulon, Kec. Dau, Kab. Malang pada hari Sabtu, 23 Maret 2019. Dihadiri oleh 42 orang yang merupakan mitra pengabdian dan semuanya berasal dari anggota kelompok tani jeruk Dusun Sempu, Gading Kulon.

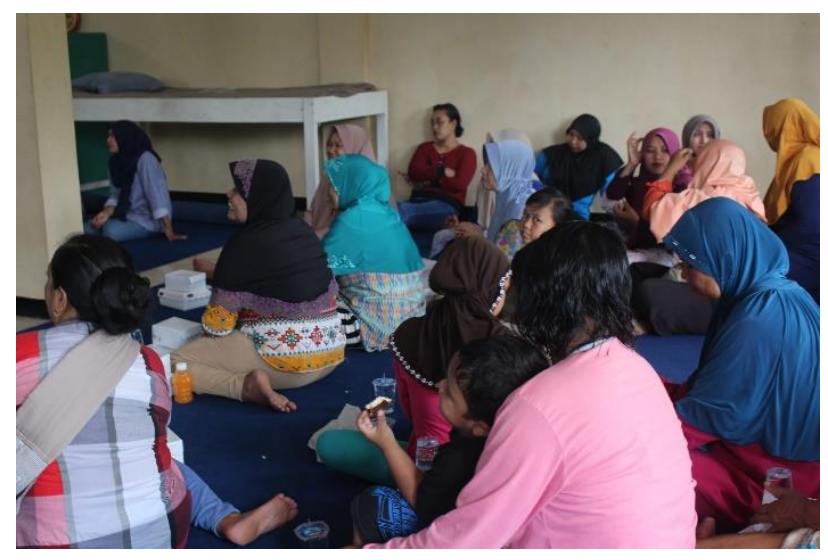

Gambar 2. Peserta Pengabdian Olahan Sari Jeruk

Tim Pengabdi membagi tiga tahap dalam proses pelaksanaan, yaitu tahap pra pelaksanaan, tahap pelaksanaan, dan tahap akhir pelaksanaan. Berikut adalah penjelasannya:

\section{Tahap Pra Pelaksanaan}

Tahap pra pelaksanaan dimulai ketika mitra mengajukan permohonan untuk menindaklanjuti proses sosialisasi pengolahan sari jeruk yang dilakukan pada pengabdian sebelumnya. Mitra meminta agar tim pengabdi melakukan sebuah kegiatan yang merujuk pada praktik secara langsung pengolahan sari jeruk. Menanggapi hal tersebut, tim pengabdi meminta kepada pakar yang ahli dibidangnya, yaitu bapak Syamsul Huda, S.P. untuk memandu mitra dalam 


\section{(A) ABDIMAS}

https://journal.uwgm.ac.id/index.php/abdimasmahakam

E-ISSN: 2549-5755

Januari 2020, Vol. 4 No. 01

praktik pengolahan sari jeruk. Bapak Huda merupakan pakar di bidang Teknik Hasil Pangan sekaligus pelaku bisnis CV Bagus Agriseta Batu.

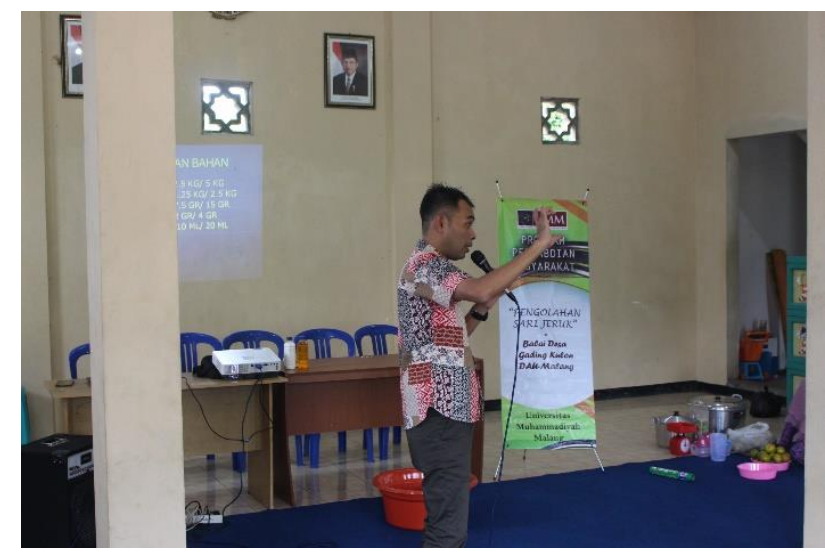

Gambar 3. Pemateri Pengabian: Bapak Huda

Setelah memastikan bahwa pemateri bersedia memandu praktik pengolahan sari jeruk, selanjutnya tim pengabdi menginfokan hal ini kepada mitra. Selain itu, tim pengabdi juga menyiapkan semua bahan, peralatan, dan perlengkapan yang diminta oleh pemateri. Berikut adalah rincian bahan, peralatan dan perlengkapan yang dibutuhkan dalam praktik pengolahan sari jeruk:

\begin{tabular}{ll}
\hline \multicolumn{1}{c}{ Kebutuhan bahan: } & \multicolumn{1}{c}{$\begin{array}{c}\text { Kebutuhan Peralatan dan } \\
\text { Perlengkapan: }\end{array}$} \\
\hline Jeruk Siam & Kompor \\
Gula Pasir & Panci Besar \\
Asam Malat & Panci Sedang \\
Pewarna & Saringan \\
Cloudy Flyer & Ember \\
Essence & Pengaduk \\
Natrium Benzoat & Sendok \\
Botol Kemasan & Timbangan Kue \\
\hline
\end{tabular}

Tabel 1. Bahan dan Perlengkapan

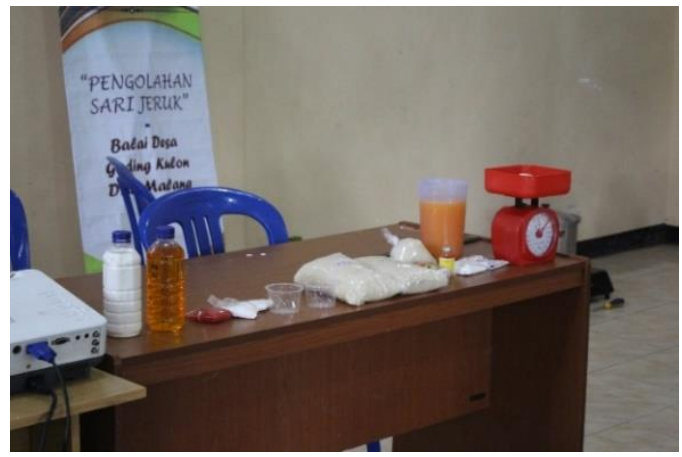

Gambar 4. Bahan-Bahan yang digunakan 


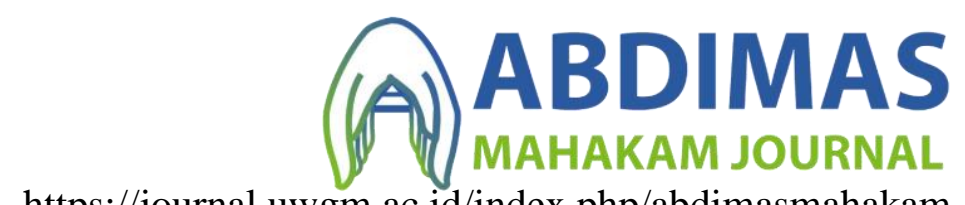

https://journal.uwgm.ac.id/index.php/abdimasmahakam

E-ISSN: 2549-5755

Januari 2020, Vol. 4 No. 01

\section{Tahap Pelaksanaan}

Sebelum menginjak pada praktik pengolahan sari jeruk, pemateri terlebih dahulu memberikan penjelasan proses pengolahan sari jeruk. Pemateri menjelaskan tahapan demi tahapan proses pengolahan sari jeruk. Pemaparan materi dilakukan selama 45 menit. Hal ini bertujuan untuk memberikan gambaran sekilas pada mitra tentang apa yang akan dilakukan. Pada sesi ini, beberapa mitra terlibat dalam proses tanya jawab dan komunikasi langsung dengan pemateri. Setelah pemaparan materi, selanjutnya proses pengolahan sari jeruk. Ini adalah kegiatan inti pengabdian. Bapak Huda selaku pemateri dibantu dengan dua orang asistennya. Proses pengolahan sari jeruk dilaksanakan selama 2 jam. Dalam proses tersebut, mitra terlibat aktif dengan dibantu oleh 2 asisten dari pemateri. Mitra terlihat sangat antusias karena ini adalah ilmu baru bagi mitra.

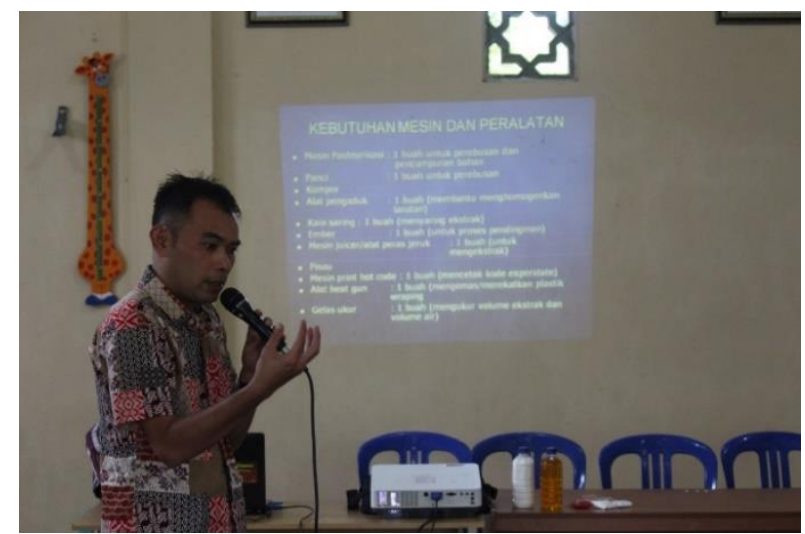

Gambar 5. Bapak Huda menjelaskan bahan-bahan yang dibutuhkan dan proses pembuatan olahan sari jeruk

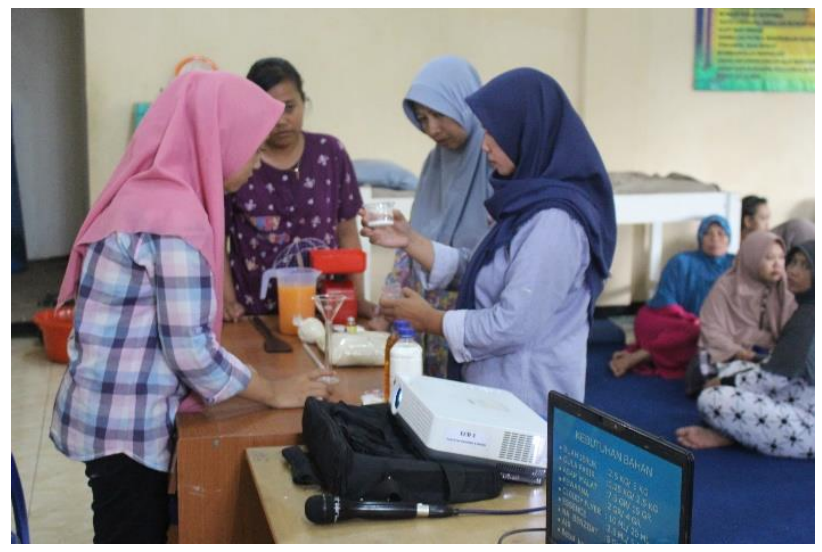

Gambar 6. Proses pencampuran bahan-bahan

\section{Tahap Akhir Pelaksanaan}

Setelah proses pengolahan sari jeruk selesei, pemateri memberikan kesempatan pada semua mitra yang hadir untuk mencoba sari jeruk yang telah jadi dan siap dinikmati. Tujuannya adalah memberikan kesempatan untuk memberikan masukan atas rasa sari jeruk yang telah diolah bersama.

Selanjutnya, pemateri membuka sesi dialog untuk mengevaluasi hal-hal yang perlu diperbaiki. Mitra memberikan tanggapan bahwa sari jeruk tersebut memiliki rasa yang sangat 
https://journal.uwgm.ac.id/index.php/abdimasmahakam

E-ISSN: 2549-5755

Januari 2020, Vol. 4 No. 01

menonjol aroma jeruknya. Pemateri menjelaskan bahwa aroma jeruk yang sangat menonjol tersebut dikarenakan perbandingan jeruk dengan air yang tidak jauh berbeda.

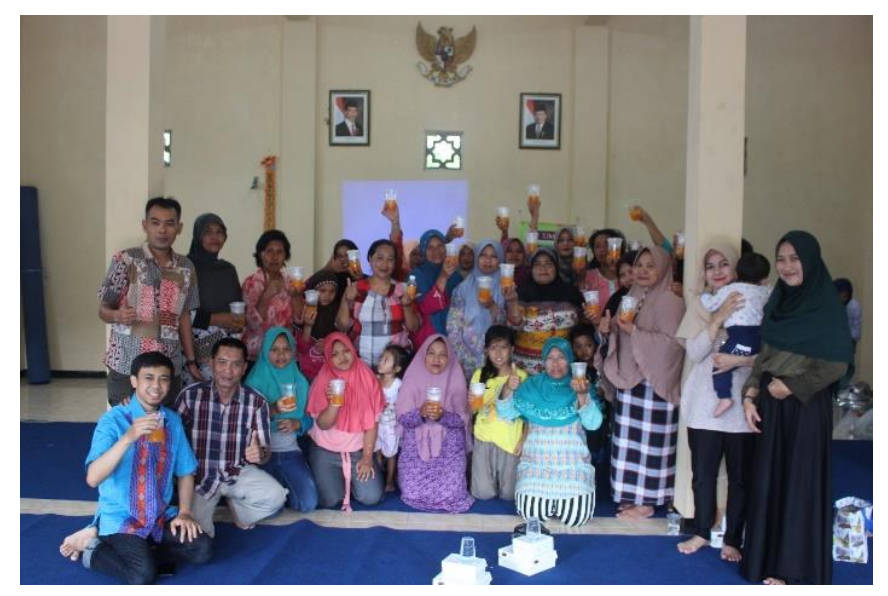

Gambar 9. Produk Olahan Sari Jeruk dinikmati oleh Peserta

Memang dari segi rasa sangat enak, tetapi kurang menguntungkan jika dilihat dari sisi bisnis. Menanggapi sisi bisnis, mitra mSemiliki tujuan kedepannya untuk menjadikan hasil olahan sari jeruk sebagai potensi home industri. Sehingga pada dialog tersebut, mitra mengungkapkan keinginannya untuk diadakan tindak lanjut lagi seperti bagaimana proses pengemasan, pemasaran sampai dikenal oleh masyarakat luas.

Sebelum kegiatan diakhiri, tim pengabdi menyerahkan semua sisa bahan, peralatan dan perlengkapan kepada mitra. Hal ini disambut hangat oleh mitra, yang pada saat itu serah terima diwakili oleh ketua kelompok tani. Harapannya dengan adanya peralatan dan perlengkapan maka kelompok tani dapat melakukan sendiri praktik pengolahan sari jeruk kapanpun.

\section{Simpulan dan rekomendasi}

Masalah Jeruk Siam yang memiliki niai atau harga rendah ketika panen raya, mampu ditingkatkan daya saingnnya dengan melakukan strategi diversifikasi produk. Diversifikasi produk berupa Olahan Sari Jeruk menjadikan Jeruk Siam menjadi lebih bernilai di mata Petani Jeruk. Secara tidak langsung, strategi ini dapat digunakan untuk mendongkrak perekonomian Petani Jeruk. Program pengabdian selanjutnya dapat berupa pendampingan pengurusan PIRT, model pemasaran, hingga pengolahan diversifikasi produk lainnya. 


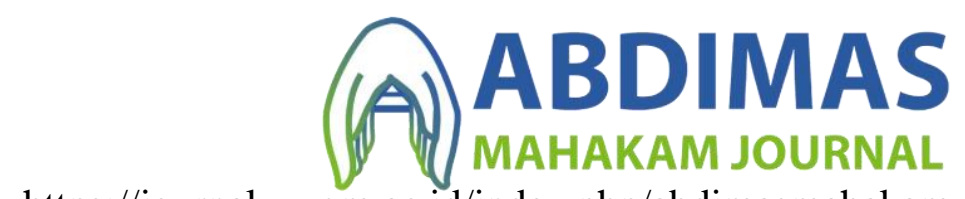

https://journal.uwgm.ac.id/index.php/abdimasmahakam

E-ISSN: 2549-5755

Januari 2020, Vol. 4 No. 01

\section{Daftar Pustaka}

Alitawan, A. A. I., \& Sutrisna, I. K. (2017). Faktor-Faktor yang Mempengaruhi Pendapatan Petani Jeruk pada Desa Gunung Bau Kecamatan Kintamani Kabupaten Bangli. EJurnal Ekonomi Pembangunan Universitas Udayana, 6(5).

Hermawan, I. (2012). Analisis eksistensi sektor pertanian terhadap pengurangan kemiskinan di pedesaan dan perkotaan. MIMBAR, Jurnal Sosial dan Pembangunan, 28(2), 135144.

Isbah, U., \& Iyan, R. Y. (2016). Analisis peran sektor pertanian dalam perekonomian dan kesempatan kerja di Provinsi Riau. Jurnal Sosial Ekonomi Pembangunan, 7(19), 4554.

Putra, H., \& Nasir, M. (2015). Analisis Faktor-Faktor Yang Mempengaruhi Produksi Sektor Pertanian Di Propinsi Aceh. Jurnal Agrisep, 16(1), 53-60. 